\title{
BUILDING BLOCKS OF INNOVATION WITHIN A STATE-OWNED ENTERPRISE (PART TWO)
}

\author{
BETSI VAN ZYL \\ GERT ROODT \\ JOHAN COETSEE \\ Department of Human Resource Management \\ University of Johannesburg
}

\begin{abstract}
In this article (the second part of a two-part study) the focus is on establishing a theoretical framework of stateowned enterprise (SOE) managers' espoused theory of building blocks of innovation. A qualitative approach, namely Grounded Theory, supported by Theoretical Sampling, was applied in generating the primary data for the study from different management levels in the SOE. The managers' espoused theory, based on empirical evidence, shows that innovation consisted of five important building blocks, namely contextual setting; strategic enablers; business enablers; foundational enablers; and human resources; each with its own categories and sub-categories. The study also identified barriers to innovation. An innovation diffusion framework, specifically for implementation in a government context, was proposed.
\end{abstract}

\section{OPSOMMING}

Die fokus van hierdie artikel (deel twee van ' $n$ tweedelige studie) is op die daarstelling van 'n teoretiese raamwerk van bestuurders in 'n staatsbeheerde onderneming (SBO) se voorgestane teorie van innoveringsboublokke. 'n Kwalitatiewe benadering, naamlik Gegronde Teorie ondersteun deur Teoretiese Steekproefneming is gebruik om die primêre data vir die studie uit verskillende bestuursvlakke van die SBO te verkry. Die voorgestane teorie wat op empiriese navorsing gebaseer is, toon dat innovering uit vyf belangrike boublokke bestaan, naamlik 'n kontekstuele omgewing; strategiese bemagtigers; besigheidsbemagtigers; grondslagbemagtigers; en menslike hulpbronne; elkeen met sy eie kategorieë en subkategorieë. Die studie het ook hindernisse vir innovering geïdentifiseer. 'n Innoveringsdiffusieraamwerk, spesifiek vir implementering in die staatsdiensomgewing, is voorgestel.

\section{Objectives of the study}

The primary empirical research objective of this article (part two of the study) is to establish a theoretical framework of SOE managers' espoused theory on building blocks of innovation. The secondary objectives of the study are to empirically determine managers' views on: 1) approaches to innovation; 2) barriers to innovation; and 3) enablers of innovation. Hereby, the primary objective of the study will be achieved, namely to compare and integrate the theoretical frameworks based on a literature review and the empirically based espoused theory of managers.

Few authors have attempted to build an integrated conceptual framework of the building blocks of innovation, although authors such as Kuczmarski (1996) admitted that many executives today, similar to him twenty years ago, have not yet figured out how to create an environment that breeds innovation. In support of these notions, leaders and/or managers required a common point of reference in the shape of a conceptual multi-dimensional framework that dealt with the complex nature of innovation, which may be used and built upon in practice and research (Cooper, 1998). Various authors stated through their discourses, their belief that innovation is the key to organisational survival and growth (Handy 1996, Drucker 1955, Hivner, Hopkins \& Hopkins, 2003; Kuczmarski 1996; McGivern \& Tvorik, 1997, Mohamed, 2002; Tucker 2003). Consequently, there is a need for the development of a theoretical framework of the building blocks of innovation (covered in the first part of the study) that can serve as a basis for comparison with managers' espoused theory of innovation, as a business practice (covered in the second part of the study).

\section{RESEARCH DESIGN}

Research approach

The study was executed using a qualitative research approach (Schurink \& Schurink, 2001), more specifically the symbolicinteractionist approach (Denzin, 1989). The design and

Requests for copies should be addressed to: G Roodt, gertr@uj.ac.za method chosen within the qualitative spectrum was Grounded Theory with a literature review according to Grounded Theory guidelines. Grounded Theory has a specific set of principles and a process to facilitate data analysis, which is supported by analytical induction and crossreferencing. Visually the design and approach of the research are presented in Figure 1.

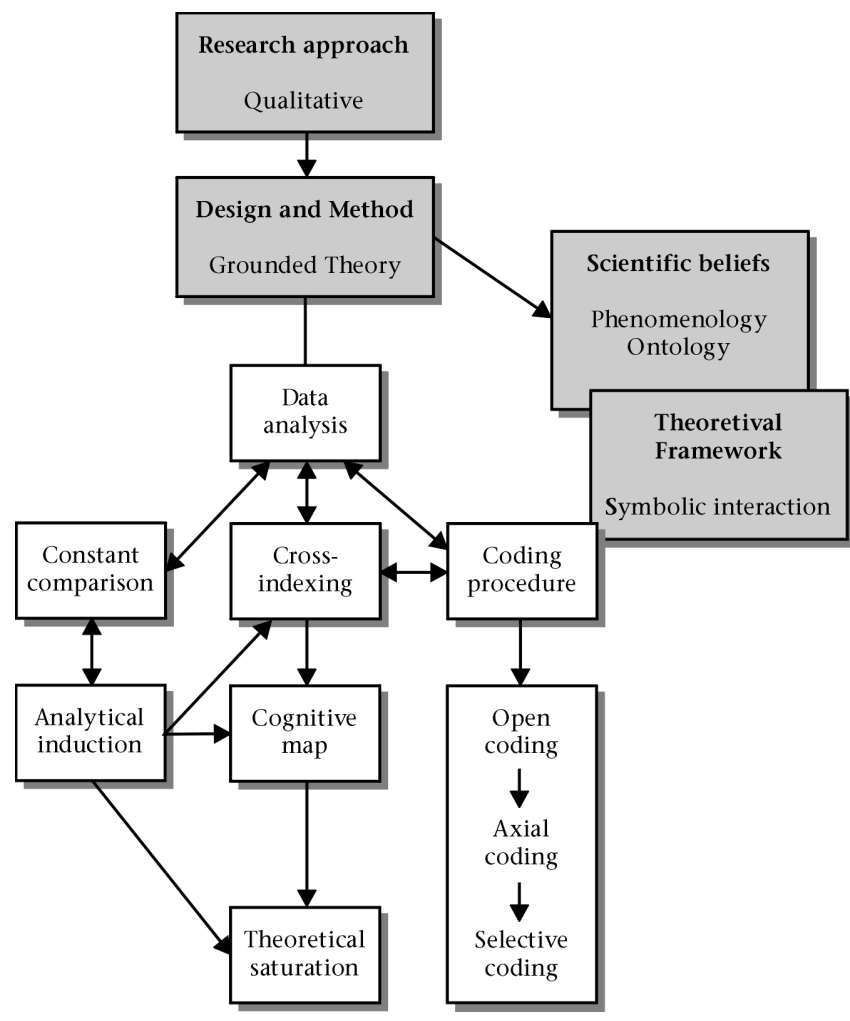

Figure 1: Summary of the research design and approach 
Research Methodology

The following six aspects will be covered under the research methodology:

\section{Participants in the study}

The participants in the study spanned hierarchical levels from junior employees to Chief Executive Officers. The breakdown of the sample is summarised below in terms of designation, job focus and gender.

TABLE 1

\section{KEY FEATURES OF THE SAMPLE}

\begin{tabular}{lllll}
\hline $\begin{array}{l}\text { Number } \\
\text { of parti- } \\
\text { cipants }\end{array}$ & Designation & Job focus & Gender & $\begin{array}{l}\text { Data collection } \\
\text { method }\end{array}$ \\
\hline 3 & CEO & Strategic & M & Direct interviews \\
1 & General Manager & Strategic & F & Direct interview \\
3 & Executive Manager & Strategic & M & Direct interviews \\
5 & Senior Manager & $\begin{array}{l}\text { Strategic/ } \\
\text { Tactical }\end{array}$ & M (4) & $\begin{array}{l}4 \text { direct interviews } \\
1 \text { correspondence }\end{array}$ \\
& Managers & Tactical/ & M (3) & 6 direct interviews \\
8 & Operational & F (4) & 2 telephonic interviews \\
& & Operational & M (5) & 3 direct interviews \\
7 & Middle Managers & F (2) & $\begin{array}{l}1 \text { telephonic interview } \\
1 \text { correspondence }\end{array}$ \\
& & & & Direct interviews \\
\hline 4 & Junior Managers & Operational & F &
\end{tabular}

Method of data gathering

The data collection took place on different, integrated levels. The initial sampling, based on theoretical sampling, focused on participants with a strategic focus with regard to their job outputs. The content of the data collected during these initial interviews indicated the most informative subjects for the next level based on progressive sampling. The sampling during this level was supported by sequential and purposive techniques, such as snowballing (Mouton \& Marais, 1996; Stewart \& Stewart, 1990). Participants on this level comprised of employees across the hierarchical spectrum of the state-owned enterprise and their job outputs were mostly tactical and operational. The results of both the initial sampling and progressive sampling directed resource sampling. Resource sampling indicated the interaction with paper-based information, such as enterprise documents, enterprise magazines, media releases, articles and books.

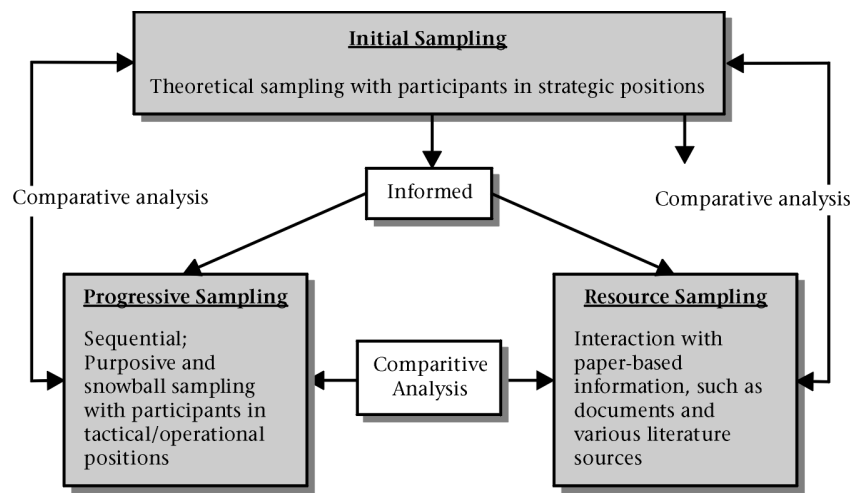

Figure 2: Graphic representation of the data collection process

Data collection procedure

The primary data collection technique was direct interviews supported by telephonic interviews and correspondence
(Mathers et al., 2002). Additional information gathering took place in the form of documentation, relevant literature studies, and books plus articles supplied by participants. Documentation and available literature analysis made important contributions through applying the comparative analysis technique.

\section{Data capturing}

Field notes were captured by using note-taking, and supported by cognitive mapping. To ensure the comprehensibility and consistency of note-taking, an electronic format was drawn up beforehand based on the Cornell system (Pauk, 1989). Cognitive mapping was used to indicate the links between concepts, as well as the raw facts contained in the notes. This method of data capturing assisted in summarising information; consolidating information from different research sources; and in structuring complex data (Swan \& Newell, 1994).

\section{Data Management}

Data was managed by using transcription and memos. Transcription, through tape analysis, meant adding to the notes taken during the interview to ensure comprehension. Word-for-word transcriptions (narratives) were not used. The idea was not to relate a narrative, but to capture the essence of the building blocks of innovation. The electronic data sheets that were developed and used for the interviews were used for this exercise as well. In effect, the written notes were transferred to the electronic version with the added information. During transcription, each interview was given a code to ensure anonymity. As themes and categories emerged they were allocated an identification code to ensure cross-referencing and retrievability. After each interview, the notes were checked and completed to ensure their completeness and understandability (Leedy \& Ormrod, 2001; Star, 1997; Strauss \& Corbin, 1990; Pandit, 1996; Parker \& Roffey, 1996).

Thoughts, important ideas and reflections were captured as "memos" as described by Strauss and Corbin (1990). Emerging theories were captured, as well as new questions that should be answered or included during consequent interviews. This was done to keep a record of personal thought processes and formed a supportive point for the analysis procedure. Keeping memos ensured that reflection and reviewing were done constantly. Inconsistencies were noted and followed up. Meaningful associations were also noted (Pope et al., 1999). Memos consisted of comments made by participants, as well as capturing personal notes on emerging relationships between categories, sub-categories and their dimensions.

\section{Treatment of the data}

Grounded Theory described a data coding system as its analysis method. An important feature is that data is categorised through codes and concepts and not numbers. The number of times that the same piece of information is categorised is not important. The focus is not to quantify the information, but to make new connections between information-rich data that will inform the emerging theory. A coding procedure was used to analyse the data of which open coding, axial coding and selective coding form part, inclusive of constant comparison, cross-indexing and cognitive mapping (Leedy \& Ormrod, 2001; Star, 1997; Strauss \& Corbin, 1990; Swan \& Newell, 1994; Pandit, 1996; Parker \& Roffey, 1996). Although these methods are mentioned separately, their application was integrated. A map (Figure 3) of all the methods and techniques used is given as a broad overview. 


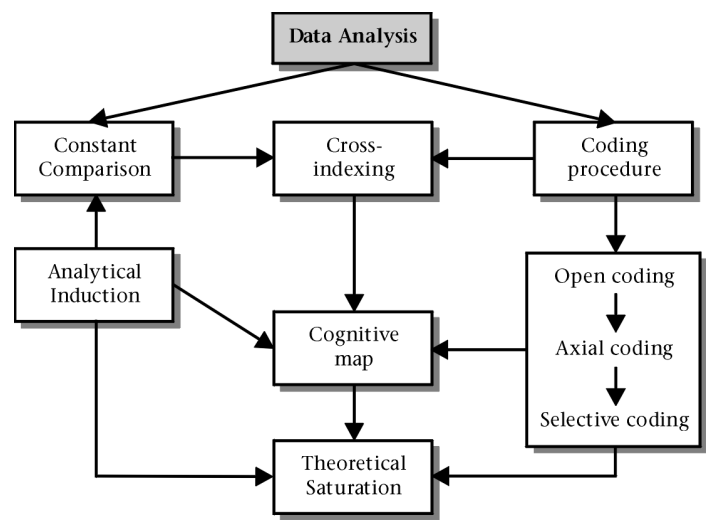

Figure 3: A map of data analysis methods and techniques used

Coding is a process of simultaneously reducing the data by dividing it into units of analysis and coding each unit. This way of data reduction is an iterative process. The coding process was ongoing and dynamic. The coding process (Leedy \& Ormrod, 2001; Star, 1997; Strauss \& Corbin, 1990; Pandit, 1996; Parker \& Roffey, 1996) consisted of specific steps, namely:

Open Coding: The objective of this step was to identify variables with regard to innovation. This step also served the purpose to guide further and more focused data collection, leading to further conceptualisation of the data and refinement of the coding schemes through Constant Comparison.

Axial Coding: This step directed the interaction (reading and rereading of the material collected) of the data. This meant that recurring concepts were studied to determine the reason for the recurrence. Informed by analytical and theoretical ideas developed through the analysis procedure, concepts are further refined and reduced by grouping them together into categories and sub-categories.

Selective Coding: The links and relationships that would give rise to the emerging theory during selective coding were established by defining groups of concepts that belonged together thematically during axial coding. Similarities and differences in compiled codes were clustered together to underpin the emerging theory.

Constant comparison: This process included four steps, namely the transcription of information received, integrating and analysing additional data, continuous modifications to the data as relationships became clearer and the theoretical explanation of the data. By using analytic induction, the emerging theory was tested against existing theory in literature, as it became relevant, as well as against further analysis of the data. Analytic induction rendered the opportunity to verify, confirm and qualify emerging concepts, categories and variables by searching through the data.

Cross-indexing: Analysis showed that some of the variables could belong to more than one category. Cross-indexing allowed the variables to be linked to the different categories.

Collection and analysis of data continued, until theoretical saturation had been reached. This point in the study occurred when no new concepts emerged from data collected or from constant comparison.

\section{RESULTS}

Owing to a lack of space, the data (descriptions) and codes obtained from the participant interviews are not included here, but can be inspected more closely in Van Zyl (2005). The data were grouped in categories, sub-categories and themes that were identified as the emerging espoused theory on the building blocks of innovation. Through constant comparison the information were reflected in a comparative table, which was integrated to formulate a comprehensive theory on the building blocks of innovation.

Managers' espoused theory of building blocks of innovation The categories, sub-categories and themes that depict the building blocks of innovation, based on the empirical findings will be briefly discussed.

The contextual setting: The contextual setting depicts the external environment that influences the business perspective of the state-owned enterprise and includes the incremental approach to innovation; the radical approach to innovation; the people approach to innovation and the technology approach to innovation.

The Strategic Enablers: These enablers depict those categories and sub-categories that could be seen to influence the state-owned enterprise on strategic level and fall under the category of clarity of purpose, namely strategy, including the strategic intent and vision, described as the future orientation of the state-owned enterprise; structure, which includes job design, crossfunctional teams, and collaboration and leadership, describing the visioning ability, leadership orientation and leadership styles of leaders within the state-owned enterprise.

The Business Enablers: These enablers depict those categories and sub-categories within the organisation that would facilitate the internal business processes to take innovation forward, such as reward and recognition focusing on morale fatigue and the innovative spirit; change management focusing on the principles thereof and on the risk of creating comfort zones; ideas generation regarded as a resource and the management thereof; knowledge management focusing on the sharing of information and the creation of knowledge as an asset; business intelligence focusing on the ability to scan the business environment; evaluation system focusing on measuring innovation and customer-orientation focusing on customer intimacy.

Foundational Enablers: The foundational enablers consist of those categories and sub-categories in the internal environment that creates the business atmosphere within which duties must be executed. The foundational enablers are culture inclusive of motivational factors; climate (having an effect on employees and customers) and the value system (trust, commitment and support).

Human Resource Enablers: The human resource enablers refer to management practices focusing on participative management, self-management; issues pertaining to the foundational enablers, as well as internal business processes; internal orientation focusing on intrapreneurship; learning focusing on individual and organisational learning (double-loop learning, continuous learning and reflective learning); skills focusing on emotional equity; creativity focusing on the support of the state-owned enterprise to such a capability; emotional maturity focusing on emotional intelligence.

Barriers refer to macro-level barriers, which include shareholding, legislation and the national market position of the state-owned enterprise; meso-level barriers which include organisational architecture such as internal politics, internal environment, management practices, change orientation, risk orientation, structural issues (bureaucracy and silo's), clarity of purpose, funding, human capital and relationship management and micro-level barriers focusing on individual level such as time pressures, financial compensation, knowledge levels, internal competition, comfort zones, inertia and thinking skills, e.g. systems thinking. All the enablers, barriers and the 
contextual setting, have to a greater or lesser degree, a reciprocal influence on one another. The framework of the espoused theory on innovation building blocks is presented in Figure 4.

\section{DISCUSSION}

The discussion of the findings will be presented as follows:

- The presentation and discussion of an integrated conceptual framework of the barriers of innovation based on the comparison of the espoused theory and the current theoretical framework based on the literature review.

- The presentation of the building blocks of innovation based on the integrated conceptual framework.

- The discussion of emerging key themes that were identified during the empirical research phase that influenced the development of an integrated conceptual framework of the building blocks of innovation; and

- The presentation of the practical significance of these findings.

The presentation and discussion of an integrated conceptual framework

Contextual Setting: The contextual setting is a result of the research focusing on the internal orientation/approach of organisations towards innovation. This includes the drivers of innovation, the external environment in which the organisation functions and the approach towards innovation.

Drivers of innovation: The findings of the empirical study showed that although innovation is not a continuous endeavour, events of innovation rather take place as discrete events. This notion is supported by the results of the literature study. In practice, the empirical study did not indicate specific drivers of innovation. However, it was found that the biggest driver of innovation within the SOE is problem solving, as it supports the strategies of cost cutting and efficiency; giving innovation the face of a discrete event.

External environment: The empirical research findings, supported by the literature review, showed that cognitive understanding of the reciprocal relationship between innovation and economic fluctuations is important to organisations. The reason is that innovation cycles and the profile of organisations impact on one another. A mature organisation with mature products, according to its "S-curve" (Abraham \& Knight, 2001), will show a specific innovation-adoption orientation. This proved to be in line with the findings of the study. An organisation should be able to pinpoint its position with relative accuracy, as this knowledge would inform creative destruction (Drejer, 2002; Clark \& Staunton, 1996). The participants of the study did not mention creative destruction, as an innovative practice, although the literature study showed that it forms an integral part of innovation and its practices.

Approaches to innovation: According to the innovation adoption model (Rogers, 1995) the SOE falls within the late majority/laggard phase. Innovation will only be adopted and diffused when it has proven to be useful, e.g. when it can be a solution to a problem or a way to achieve efficiency. This conservative orientation results in incremental innovation, where the innovation is relatively risk-free and is mainly focused on solving problems of efficiency and maintaining/upgrading the SOE's ageing infrastructure. By following an incremental approach to innovation, the SOE adheres to its cost-saving strategy supported by the empirical

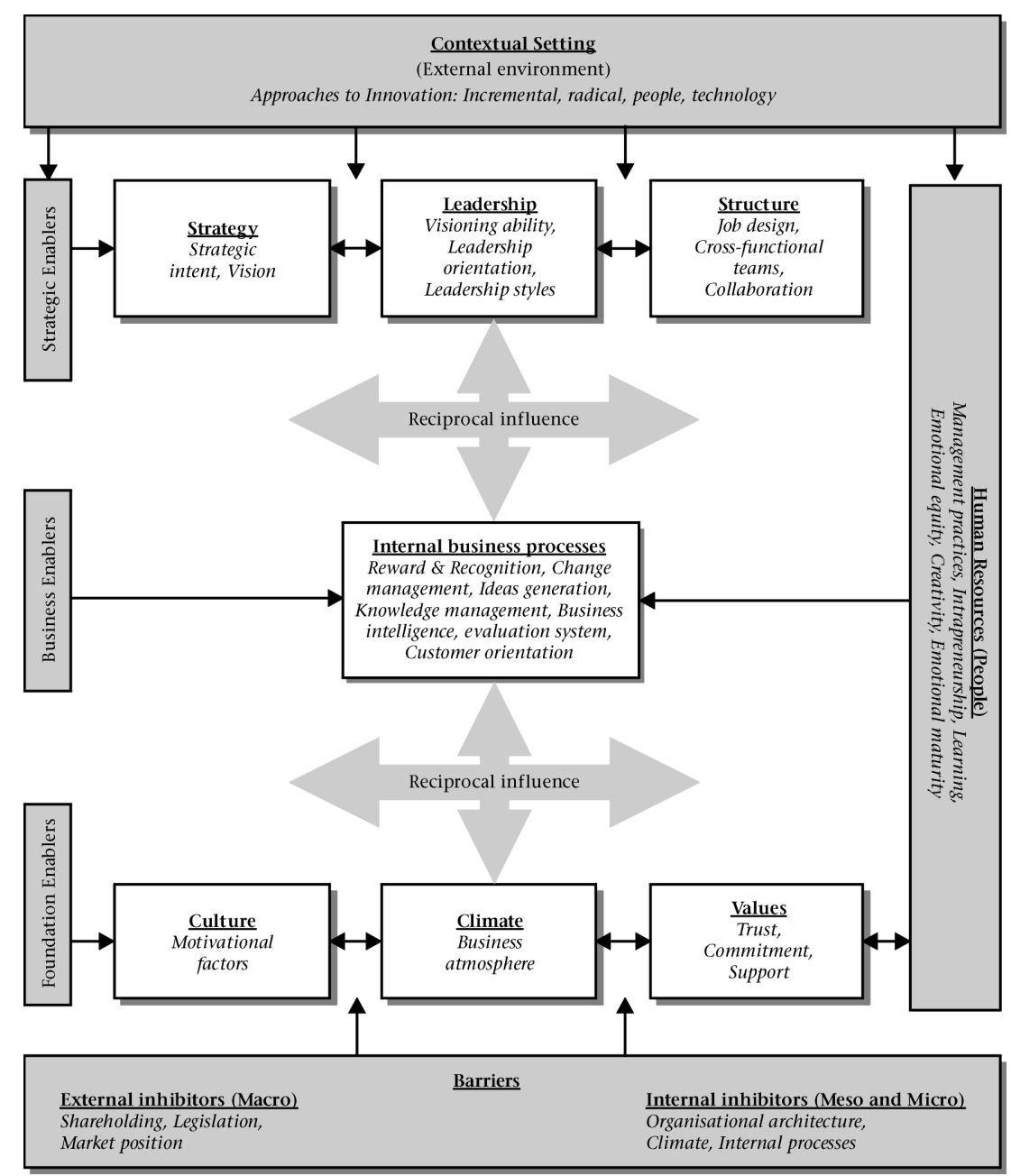

Figure 4: The SOE managers' espoused theory on building blocks of innovation 
findings that showed innovation as not being a grand strategy of the SOE, but being regarded only as an organisational value, which is not pursued actively in the operational sense. Mr Radebe, Minister of Transport, (2004) indicated that: "The underlying purpose of any transport system is to move people and goods efficiently, as cheaply as possible ..." (South African Transport Conference, p. 1). These words confirm and emphasise the strategies of cost cutting and efficiency as indicated in the findings. These strategic approaches influence the internal attitude and orientation towards innovation; hence innovation only takes place as and when problems need to be solved as opposed to being a natural inclination of doing business.

According to the "S-curve" theory (Abraham \& Knight, 2001) the maturity stage of the SOE also fits the incremental, conservative approach to innovation. The focus of the SOE is on efficiencies and not on conquering or pioneering radical innovations. However, focusing only on incremental innovation could lead to a negative response to market fluctuations and reduced sales velocity. The findings of the study indicated that market loss has been taking place at a rate that raised concern within the SOE. The current monopolistic market position of the SOE creates the impression that it has a captive market. Hence, the enterprise believes that it does not need radical innovations that change business models or alter markets. Its product and service offerings are mature and only improvements are made or redevelopment takes place, but not market altering changes as experienced through radical innovation.

Furthermore, it became clear that the innovations that are adopted are mostly technology-based. According to Freeman's study (Freeman, 1982), when organisations are in stagnation, they tend to favour innovation based on technology that has been developed external to the organisation. It is important to note that although the SOE fits the typical mature organisation profile with its typical economic impact, the literature review also emphasised how important innovation is, and that organisations need to reinvent themselves continually. Cooper (1998) suggested that mechanistic organisational structures (bureaucracies) favour incremental innovation.

Barriers/inhibitors to innovation: Barriers/inhibitors towards innovation showed the notion that barriers and enablers of innovation are different sides of the same coin. The barriers based on the literature review focused mainly on internal barriers to innovation, such as rigid strategic planning, culture, leadership, structural inhibitors, intolerance, strategic gridlock and tunnel vision (Andriopoulos, 2001; Arias, 1995; Borins, 2002; Buchen, 2003; Gurteen, 1998; Kilroy, 1999; Kono, 1988; Tucker, 2002; Quinn et al., 1997). The results of the empirical study posed barriers on three levels, namely macro (national), meso (organisational) and micro (individual) level. With regard to barriers that will inhibit innovation, those cited by the participants and those cited through the literature review are quite generic and universally applicable to most organisations. The difference is in the degree to which these inhibitors are applied and enforced.

The enablers of innovation: The individual enablers of innovation from the empirical findings compared positively with the enablers that were indicated through the literature review as these building blocks could be regarded as generic in nature.

Foundational Enablers/Business Atmosphere Enablers: The foundational enablers that emerged from the empirical findings correspond with the business atmosphere enablers indicated by the literature review. Both empirical findings and literature review emphasised organisational culture (Ahmed, 1998; Andriopoulos, 2001; Brooking, 1997; Martins \& Terblanche, 2003; Tucker, 2002) climate (Ahmed, 1998; Buckler, 1996;
Cooper, 1998; Kono, 1988) and values (Arad et al., 1997; Gratton, 2000; Johnson, 2001). The empirical findings showed more emphasis on the category dealing with climate as opposed to the reviewed literature that paid more attention to culture. The reason could be two-fold:

- Culture and climate could have been used interchangeably.

- Climate is focused on more as the practical and individual impact of climate is more immediate and tangible on the workforce.

Both the empirical findings and literature review indicated values to be an important enabler, and as can be seen from the findings of the empirical study, innovation is cited as a value of the SOE.

Business Enablers/Business Process Enablers: The empirical findings indicated specific processes that were deemed important if innovation was to take place consistently within the SOE. It was felt that, although these processes were cited, some of them might not be currently in operation and many of these processes cited were based on theoretical knowledge as opposed to current practice. Therefore, the business enablers are more of a "should be". The important processes mentioned by the participants were supported by the literature as business process enablers (Buchen, 2003; Cooper, 1998; Darroch \& McNaughton, 2002; Henry, 2001; Justesen, 2001; Kaplan \& Norton, 2004; Senge, 1990; Tucker, 2002; Uecke, 2002). Most of the categories seem to be similar. However, the literature review yielded more categories and those should be added to this dimension, as it would serve to enrich the integrated framework of innovation building blocks.

Strategic Enablers/Business Management Enablers: The strategic enablers of the empirical findings were supported by the literature review. There was a difference in the clustering of the categories. The empirical findings tended to cluster strategy and structure linked to leadership. The literature review cited structure (Andriopoulos, 2001; Cooper, 1998; Martins \& Terblanche, 2003; McAdam \& McClelland, 2002; Urabe et al., 1988; Quinn et al., 1997), leadership (Andriopoulos, 2001; Clark \& Staunton, 1990; Judge et al., 1997; Quinn et al., 1997; Tucker, 2002; Uecke, 2002) and management practices (Buchen, 2003; Cooper, 1998; Peters \& Waterman, 1982; Senge, 1990) as important components of innovation. The literature review revealed in vast amounts of information on these subjects as disciplines in their own right. The empirical findings also showed that management practices were viewed as a human resource enabler rather than a strategic enabler.

Human Resources/Human Enablers: Both the empirical findings and the literature review suggested that people are an important enabler of innovation. Both the empirical findings and literature review yielded similar categories within the human resource domain, with major emphasis on emotional intelligence and creativity. The literature review dealt with creativity from a focus point of the various skills that underpin creativity (Ahmed, 1998; Cooper, 1998; Gratton, 2000; Henry, 2001; Juniper, 1996; Klemm, 2004; McAdam \& McClelland, 2002; Quinn et al., 1997; Zhuang et al., 1999), while the empirical findings have a strong underpinning of the influence that the appropriate climate yields. Both the empirical findings and literature review have cited the importance of specific skills, mental attitude and a specific approach to doing business. In the case of the literature research huge volumes of information was available on pure entrepreneurship and less on intrapreneurship. The empirical findings focused more on intrapreneurship. With regard to the skills cited, the literature review gave a description of more specific skills, whereas the empirical findings emphasised that skills in the broad sense are important.

Emotional intelligence can be deemed an important enabler towards a framework of innovation building blocks (Gratton, 2000; Goleman, 1995; Sy \& Côte, 2004). The empirical findings 
emphasised emotional equity and emotional maturity. It seems that effective innovation depends on disciplined management systems and processes, starting with an appreciation of people and their skills.

Structural Enablers: Both the empirical findings and the literature review yielded similar structural enablers (Andriopoulos, 2001; Cooper, 1998; Martins \& Terblanche, 2003; McAdam \& McClelland, 2002; Urabe, 1988; Quinn et al., 1997). The literature review showed that appropriate structural designs for various contexts, including innovation, should be applied. The emphasis in the SOE is rather on more rigid structural enablers.

\section{The building blocks of innovation based on the integrated conceptual framework}

It was clear that no integrated conceptual framework existed in the state-owned enterprise that was researched, as innovation is only stated as a value and not an actionable objective (Strategy Document, 2002-2007). As stated by Cooper (1989) a need for a common point of reference is essential in bureaucracies. This supports the notion that an integrated conceptual framework should be developed in a state-owned enterprise that pinpoints the building blocks of innovation to ensure that innovation, as a business practice, can become a natural part of doing business as opposed to being just a problem-solving tool.

As a consequence, a conceptual framework of the building blocks of innovation based on the empirical findings and enriched by the literature review was developed through the results of constant comparison, integration and the reflections of both the literature and the empirical frameworks. A discussion of the content of the integrated framework depicting the building blocks will follow:

The Contextual Setting, as the first building block, depicts the external environment that influences the business perspective of the SOE and includes the following:

- The approach to innovation which is incremental;

- The market position of the enterprise based on S-curve and innovation adoption and diffusion theories; and

- The drivers of innovation which is problem-solving.

The Strategic Enablers, as the second building block, depict those categories and sub-categories that could be seen to influence the SOE on strategic level, such as:

- Strategy, including the strategic intent and vision, described as the future orientation of the state-owned enterprise;

- Structure, which includes job design, cross-functional teams, and collaboration, as well as networks taking into cognisance the real threat of strategic gridlock; and

- Leadership, describing the visioning ability, leadership orientation and leadership styles of leaders within the SOE inclusive of the leadership habits, such as reading and having a culch bag of ideas.

The Business Enablers, as the third building block, depict those categories and sub-categories within the organisation that would facilitate the internal business processes to take innovation forward, such as:

- Reward and recognition focusing on the change of morale fatigue into a challenging innovative spirit inclusive of the broader performance management discipline;

- Change management focusing on the principles thereof and on the risks of creating comfort zones;

- Ideas generation regarded as an innovation resource and the management thereof;

- Knowledge management focusing on the sharing of intelligent information and the creation of knowledge as an asset;

- Business intelligence focusing on the ability to scan the business environment for informative trends, opportunities and disasters;
- Evaluation systems focusing on measuring innovation appropriately;

- Customer-orientation focusing on customer intimacy;

- Relationship management internally and externally based on underlying issues, such as financial and psychological;

- Quality management in order to lay the foundation for a positive innovative environment;

- Communication management as an influence to promote creativity and innovation in a transparent environment; and

- Diversity management to optimise creativity and innovation within the SOE.

Foundational Enablers, as the fourth building block, consist of those categories and sub-categories in the internal environment that creates the business atmosphere within which duties must be executed. The foundational enablers are:

- Culture inclusive of motivational factors;

- Climate as having an effect on employees and customers; and

- A value system which emphasises trust, commitment and support.

Human Resource Enablers, as the fifth building block, refer to those categories and sub-categories that deal with the human or people element, such as:

- Management practices focusing on participative management and self-management;

- Issues pertaining to the foundational enablers, as well as internal business processes;

- Internal orientation focusing on intrapreneurship;

- Learning focusing on individual and organisational learning, e.g. double-loop learning, continuous learning and reflective learning;

- Skills focusing on the establishment of emotional equity -i.e. emotional capital;

- Core Skills focusing on "T-shaped" skills, which is a deep vertical knowledge and strong lateral associative skills;

- Hybrid thinking that involves three types of thinking, namely intuitive thinking where information stimulates the mind to produce an idea, formative thinking where insight is used to mould the idea into a concept (value proposition) and logical thinking where the idea is evaluated sensibly (customer value analysis);

- Systems thinking that would ensure vertical and horizontal alignment of the innovative activities with the strategies of the organisation;

- Creativity focusing on the support of the SOE to create and maintain such a capability; and

- Emotional maturity focusing on emotional intelligence and its components.

Barriers, included in the framework, refer to internal and external inhibitors to innovation, such as:

- Macro-level barriers, which include shareholding, legislation and the national market position of the state-owned enterprise;

- Meso-level barriers which include organisational architecture such as internal politics, internal environment, management practices, change orientation, risk orientation, structural issues (bureaucracy and silo's), clarity of purpose, funding, human capital and relationship management; and

- Micro-level barriers focusing on individual level such as time pressures, financial compensation, knowledge levels, internal competition, comfort zones, inertia and thinking skills, e.g. systems thinking.

A visual presentation of the integrated conceptual framework of the building blocks of innovation is set out below in Figure 5 .

\section{Emerging key themes}

Specific themes emerged from the results that could influence the current and future innovation practices within the SOE. The themes identified were, cost cutting and efficiency; problembased innovation; incremental versus radical innovation; 


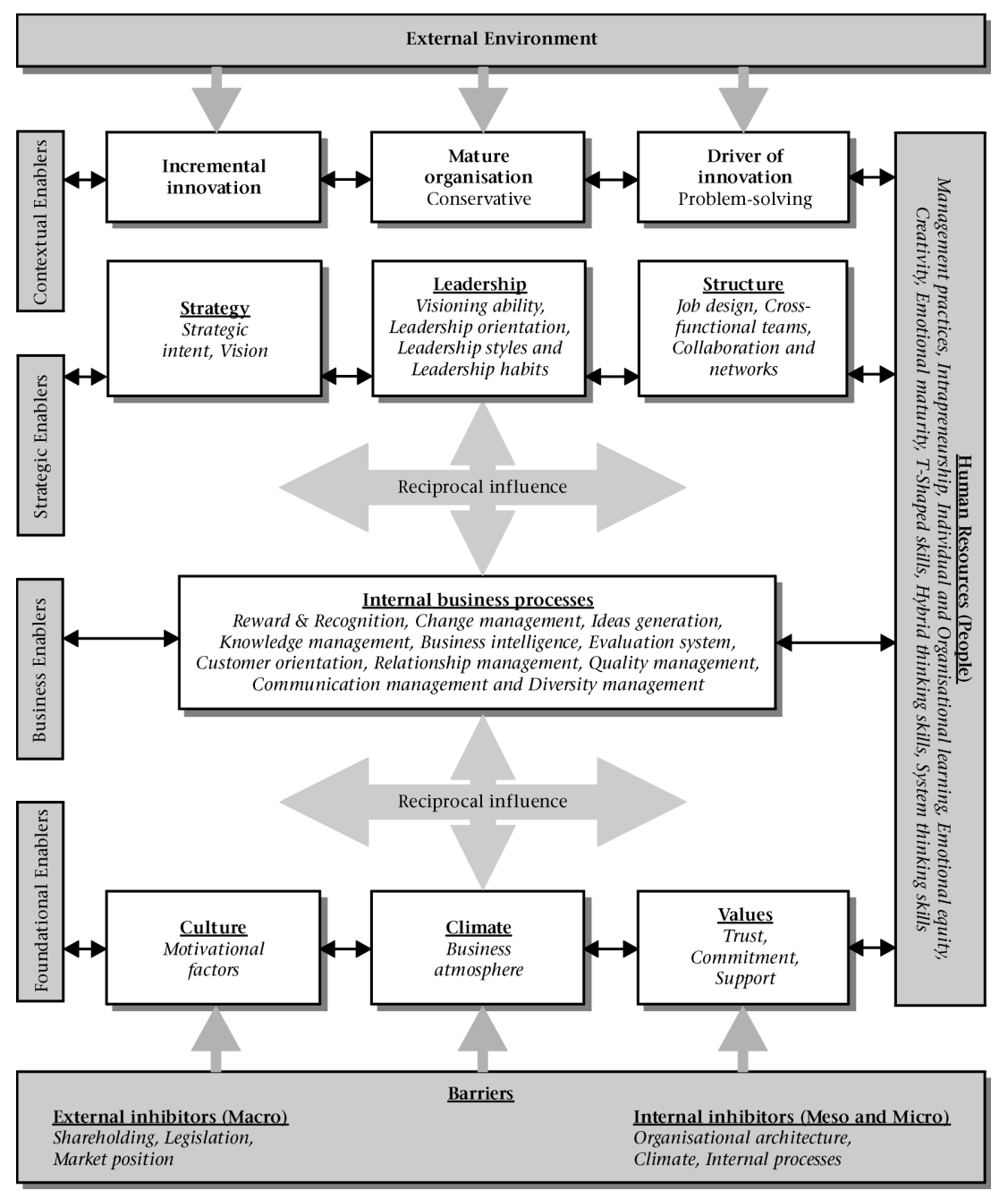

Figure 5: An integrated conceptual framework on building blocks of innovation in the SOE

fragmentation; and the internal attitude towards innovation. The following themes that were supported with examples of innovation occurred in the SOE:

Theme One - Cost saving/cutting and efficiency: This fits the image and position (both market and public) of the SOE as a national transport entity. The cost-saving and efficiency strategies also fit in with the more risk-averse approach where innovation is concerned, because any investment is exposed to intense public scrutiny. Innovation that occurred within the SOE is in support of cost cutting or efficiency. By applying the principles of the "Scurve" methodology, a mature product life cycle would mean that the SOE would focus on cost cutting and improving productivity.

Theme Two - Problem-based innovation: Innovations cited as examples during the study were all problem-based. In other words, when a problem occurs, a solution would be pursued. In some instances those solutions are creative, resulting in an innovation. Hence, problem-solving is seen as the main driver of innovation as opposed to creating new business.

Theme Three - Incremental versus radical innovation: If innovation only occurs after a problem has been identified, it could be interpreted as reactive innovation. The findings of the study suggested that the SOE has a tendency to follow a more incremental approach to innovation as opposed to a radical approach. This also fits in with the overall conservative approach that is believed to exist within the SOE, as well as with its cost-saving strategy, where the innovations that were cited are technology-based which supports the maintenance of the ageing infrastructure. This supports the incremental approach to innovation, which focuses on maintaining the infrastructure rather than changing it dramatically. Furthermore, innovation that takes place as a reaction to a problem influences the diffusion of the innovation throughout the enterprise as it is time and space-bound. Incremental innovation supports the mature profile of the SOE and consequently its strategies. The whole focus is more on being adaptive as opposed to being radical. The leadership of the SOE has also been perceived as being conservative. It would seem that a conservative mindset focuses more on maintaining than on innovation.

Theme Four - Fragmentation within the SOE: The SOE's lack of embracing innovation as a business discipline and not just as a problem-solution tool is aggravated by the structure of the SOE which is fragmented and not approached as "one system". It could create the impression that innovation is not pursued in an integrated, continuous manner, but that innovation occurs in a fragmented way. For example, employees in the SOE know about internal innovations only because it made national headlines and not because the process of innovation was shared throughout the enterprise. The SOE was described by the participants as a bureaucracy with hierarchical levels focusing on rules, structure (levels), and authority (status). It could be argued that the bureaucratic structure with its typical hierarchies fits the strategies of the SOE (cost saving, maintenance and efficiency). It is also common in mature organisations that the structure reflects the context in which it operates, e.g. transport is a regulated environment.

Theme Five - Internal attitude towards innovation: The results suggested that the application of creativity within the SOE is reactive. This form of creativity is demand-driven and surfaces 
when problems arise. Many creativity efforts are carried out for selfpreservation rather than to improve services. Reactive creativity is the consequence of factors that tend to undermine intrinsic motivation. This became clear when the participants were asked to identify possible building blocks for innovation. It was approached from a negative viewpoint at first. This means that the building blocks were identified as barriers first. Also, when prompted, the building blocks were identified in a very mechanistic manner. This supports the notion that innovation is not part of the daily business routine. The barriers are seen as negative aspects as opposed to positive aspects of the building blocks. If innovative practices, utilising the innate creativity of every person, is not practiced daily, it could be a source of frustration amongst employees, hence, the negative initial approach.

\section{Practical Significance}

The themes discussed above, currently exist in the SOE and would have a determining influence on innovative activities within that enterprise. The huge infrastructure (bureaucratic and fragmented), that is basically funded by the taxpayer, would and could not be changed overnight. Therefore, to promote continuous innovation, the building blocks of innovation should fit into the current architecture of the SOE in order to facilitate the adoption and diffusion of innovation and its practices. With this in mind, a diffusion framework was developed to assist with the dissemination of innovation and its practices inclusive of the building blocks of innovation. This diffusion framework of innovation is proposed to fit into the typical passive, hierarchical bureaucratic structure of the SOE, where innovations that do take place are not diffused throughout the fragmented structure of the SOE. Hence, the emergent building blocks of innovation can be superimposed onto a diffusion framework of innovation.

The proposed diffusion framework can change the passive hierarchy into a pro-active one by creating communities of practice to promote innovative practices on existing organisational levels. The approach is to reconfigure the hierarchical structure as a current limitation into an adaptive hierarchical structure. This is in support of the notion that innovation is an adaptive system. Therefore, as the SOE is currently a fragmented bureaucracy, the various hierarchical levels should be used, not to divide (mechanistically), but to reinforce integration (actively) between the levels of the framework. The interrelationships of the emerged building blocks of innovation, linked to each level, should be harnessed to create an appropriate climate for innovation to become a daily business practice. In this sense, the existing structure of the SOE is not changed, but architecture is created that will counteract fragmentation and rigidity, which had been cited as barriers, both by the empirical findings of the study and supported by the literature review. In effect, the same structure must be harnessed as a different set of relationships, e.g. communities of practice as opposed to functional silos. Each of the levels of the framework will be discussed sequentially.

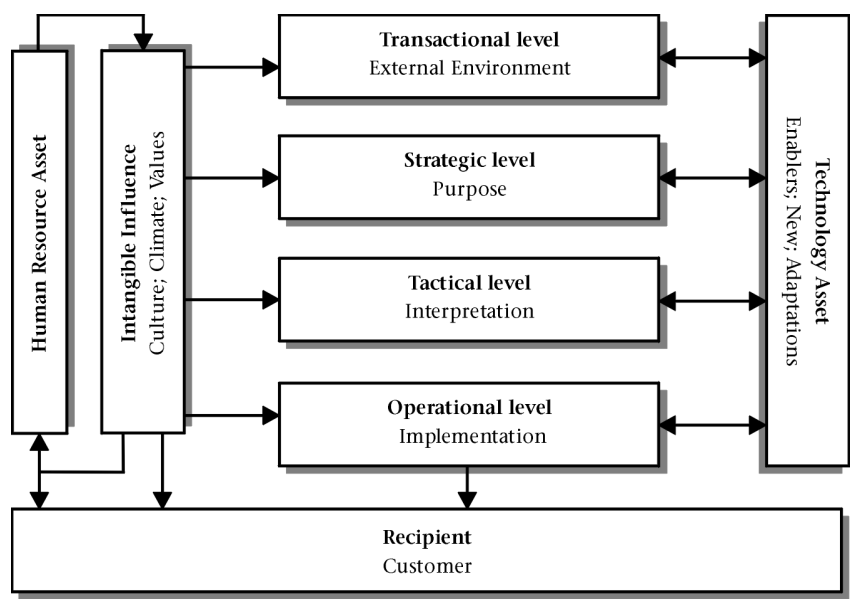

Figure 6: Proposed diffusion framework of innovative practices within the SOE
The levels must be interpreted as a layered network, based on systems-thinking principles. An activity on one level will crossimpact on all the other levels as depicted in Figure 6. In this way, the structure can be applied intelligently as opposed to being debilitating with regard to innovation.

Innovation is initiated on the transactional level. The enterprise is in constant dialogue with its external environment. The result of that dialogue is communicated tangibly and intangibly to all the other levels, such as the strategic level, the tactical level and the operational level.

The strategic level refers to the building blocks of strategy, structure and leadership. Leadership, starting with executive leadership, should support innovation through its visioning ability. This is the ability to recreate current activities towards a future need. The visioning ability is fed by the communication that the enterprise has with its external environment as determined by the transactional level. This ability is supported by the ability to share this vision as described through clarity of purpose. When this is communicated, shared and understood through a powerful vision, the enterprise could be moved from its reactive state to a more proactive state. Clarity of purpose, when managed well, counteracts unfocused activities resulting from employees not having goal clarity, which was cited as a barrier. Genuine inquiry and an entrepreneurial attitude will counteract barriers, such as being directive and controlling.

As new business development is stated as one of the business objectives and new business is implied in the SOE, a growth strategy would be needed. A growth strategy needs innovation. An innovation strategy, with an innovation framework would provide the clarity of purpose. It should be stated in more direct operational terms as opposed to being just a value, as is the current situation. This innovation strategy would form the necessary link to the next level, namely the tactical level. The tactical level has as its purpose the interpretation of the outcomes of decisions on the strategic level. The shape of the enterprise could facilitate innovation. Although it would not make sense to suddenly change the current physical shape of such a huge entity (fragmented, bureaucratic and hierarchical), new approaches to execute duties could counteract the "heaviness" and slowness of the enterprise. Project teams, consisting of cross-disciplinary team members could function in the same way as many small companies. This approach would also counteract the "silo mentality", comfort zone syndrome and destructive internal competition. Diversity within the teams would challenge and boost creative approach to the task at hand. This incremental approach could facilitate a more integrated enterprise. The enterprise must design the infrastructure in such a way that it will support and strengthen innovation and its practices.

The tactical level comprises management practices, including the management of the innovation value chain. Participative management should maintain that thin balance between chaos and stability, which is an innate part of any innovation process. Participation and support would create and maintain motivational factors that would support practices leading to innovation. Participation would also counteract destructive internal competition and debilitating organisational politics. Participation is in effect the opposite of command and control. Changes are inevitable when innovation is in progress. By approaching any change as a process based on specific principles, the usual turmoil that accompanies it can be minimised and it could be less disruptive in a negative way. The operational level needs to execute the results of the strategic and tactical level.

The operational level refers to the business processes and the accompanying systems that create the channel through which the input towards a possible innovation can result in a specific output. Therefore, the processes and systems must be conducive 
to innovative practices. These systems and processes are technology based. To support and facilitate innovation, all processes must be directed at focusing from all possible sources those elements that would lead to an innovation. There must be a concerted effort to capture and evaluate all ideas (idea management); to share learning (networks, teams); to tap into knowledge (knowledge management); and to use all of these when opportunities arise (business intelligence). All of these processes eventually feed back into the strategic level, which is influenced by the transactional level.

The whole diffusion framework (Figure 6) is interlinked and interdependent through three variables, namely the intangible influence, the human resource asset and technology asset variables. These variables can be seen as initiators and recipients of innovation as innovation is dependent on people and is, in the case of the SOE, mainly technology-based. It is also indicative of instability based on technology change and people mobility. The intangible influence is indicative of the biggest area concerning resistance to change.

Culture, climate and values form the intangible influence that impact on all levels of the internal environment of the SOE. The intangibles form the organisational foundation for innovation. The SOE must have a supportive internal environment (business atmosphere) conducive to innovative practices. Conduciveness was explained in the sense of trust, time and understanding. Trust is built or destroyed by what is modelled by the leadership of the enterprise. The intangibles are a manifestation of how the SOE presents itself to the external environment. If the customer perceives the SOE to be innovative, this in itself can stimulate a demand. Errortolerance will feed more calculated risk-taking.

Human resources are regarded as an asset based on their skills, knowledge and their intangible influences. As an asset it impacts on innovation through the effect leadership has on innovation and its practices; the effect the managerial dimension executes; the effect the employees have on innovation and its practices; and the effect customers have on the innovation presented.

Employees are driven as much by their emotions as by their intellect. To be truly innovative, the SOE must ensure that there is emotional equity. Emotional equity refers to a "fit" between what is important for the individual and what is important for the enterprise. This "fit" ensures that individual and organisational objectives are met. Elements that would contribute to emotional equity are personal attitude, culture and climate, challenges, level of creativity, level of empowerment, emotional maturity, level of appropriate skills and learning orientation. Employees cannot be inventive within an enterprise where risk is seen as a barrier, or where inertia is acceptable.

Technology (as an asset) can take the form of an enabler for the business processes depicted on the operational level, or it could be new technology implemented to solve problems or save costs. It could also be adaptations to existing technology within the SOE. Each level depicted in the framework utilises technology differently.

An innovation is only useful if it is used by the customer. To ensure that innovation adds to the bottom-line of the SOE, innovation should be customer-driven. Input is needed from the customer and there must be interaction between the SOE and the customer on all the levels indicated in the diffusion framework. Poor service levels could be counteracted if customers are seen to be part of the SOE.

\section{Conclusion}

It would seem that while many organisations subscribe to the importance of innovation, few have been able to maintain a culture that supports innovation as a top strategic priority. The vital importance of continuously fostering and maintaining an innovation culture needs to be realised in the current business environment. The study, for the benefit of the SOE, must be repeated at chosen intervals, as innovation is a dynamic phenomenon. Therefore, its building blocks would also be dynamic and would need to be up-dated according to changes on macro-, meso-, and micro-levels.

\section{REFERENCE}

Abraham, J.L. \& Knight, J.D. (2001). Strategic Innovation: Leveraging creative action for more profitable growth Strategy \& Leadership, 29 (1), 21-27.

Ahmed, P.K. (1998). Culture and Climate for Innovation. European Journal of Innovation Management, 1 (1), 30-43.

Andriopoulos, C. (2001). Determinants of organisational creativity: a literature review. Management Decision, 39 (10), 834-841.

Arad, S., Hanson, M.A., Schneider, R.J. (1997). A framework for the study of relationships between organizational characteristics and organizational innovation. The Journal of Creative Behavior, 31 (1), 42-58.

Arias, J.T.G. (1995). Do networks really foster innovation? Management Decision, 33 (9),52-56.

Borins, S. (2002). Leadership and Innovation in the Public sector. Leadership and Organization Development Journal, 23 (8), 467-476.

Brooking, A. (1997). Intellectual Capital. London: International Thomson Business Press.

Buckler, B. (1996). A learning process model to achieve continuous improvement and innovation. The Learning Organization, 3 (3), 31-39.

Buchen, I.H. (2003). Future-imbedded innovation methodologies. Foresight, 5 (3), 3-9.

Clark, P. \& Staunton, N. (1990). Innovation in Technology and Organization. London: Routledge.

Cooper, J.R. (1998). A multidimensional approach to the adoption of innovation. Management Decision, 36 (8), 493-502.

Darroch, J. \& McNaughton, R. (2002). Examining the link between knowledge management practices and types of innovation. Journal of Intellectual Capital, 3 (3), 210-222.

Denzin, N.K. (1989). The research act: A theoretical introduction to Sociological methods. Englewood Cliffs, NJ: Prentice-Hall.

Drejer, A. (2002). Situations for innovation management: towards a contingency model. European Journal of Innovation Management, 5 (1), 4-17.

Drucker, P.F. (1955). The Practice of Management. Suffolk: Pan Books.

Freeman, C. (1982). Innovation and Long-cycles of economic development. Conference paper: International Seminar on Innovation and Development at the Industrial Sector. 25-27 August, University Campinas. Retrieved from the World Wide Web on 07/05/2003: http://www.catlibraries.org.

Goleman, D. (1995). Emotional Intelligence: Why it can matter more than IQ. London: Bloomsbury.

Gratton, L. (2000). Living Strategy: putting people at the heart of corporate purpose. Financial Times/Prentice Hall.

Gurteen, D. (1998). Knowledge, creativity and Innovation. Journal of Knowledge Management, 2 (1), 5-13.

Handy, C. (1996). Beyond Certainty: the changing worlds of organisations. London: Arrow Business Books.

Henry, J. (2001). Creativity and Perception in Management. London: Sage Publications.

Hivner, W, Hopkins, W.E. \& Hopkins, S.A. (2003). Facilitating, accelerating, and sustaining the innovation diffusion process: an epidemic modeling approach. European Journal of Innovation Management, 6 (2), 80-89.

Janszen, F. (2000). The Age of Innovation: making business creativity a competence, not a coincidence. London: Prentice-Hall.

Johnson, D. (2001). What is innovation and entrepreneurship? Lessons for larger organisations. Industrial and Commercial Training, 33 (4), 135-140. 
Jones, T. \& Kirby, S. (2002). Taking Ideas to Market. UK: Capstone Publishing.

Judge, W.Q., Fryxell, G.E. \& Dooley, R.S. (1997). The new task of R\&D management: creating goal-directed communities for innovations. California Management Review, 39 (3), 72-85.

Juniper, D. (1996). Human Resource and creativity. Work Study, 45 (7), 15-22.

Justesen, S.L. (2001). Innoversity. Masters Thesis in Intercultural Management. MPP Working Paper No. 6/2001.

Kaplan, R.S. \& Norton, D.P. (2004). Strategy Maps. Converting intangible assets into tangible outcomes. Boston: Harvard Business School Press.

Kilroy, D.B. (1999). Creating the Future: how creativity and innovation drive shareholder wealth. Management Decision, 37 (4), 363-374.

Klemm, W.R. (2004). Leadership: Creativity and Innovation. Conference paper: Concepts for Airforce Leadership (AU-24). Retrieved from the World Wide Web on 07/05/2003: http://www.au.af.mil.

Kono,T. (1988). Factors affecting the creativity of organizations: an approach from new product development. In Urabe, K.; Child, J.;Kagono, T. Walter de Gruyter (eds.) Innovation and management: International comparisons. Berlin. 105-144.

Kuczmarski, T.D. (1996). Fostering an innovation mindset. Journal of Consumer Marketing, 13 (6), 7-13.

Leedy, P.D. \& Ormrod, J.E. (2001). Practical Research: Planning and Design. New Jersey: Merrill Prentice Hall.

Mathers, N., Fox, N. \& Hunn, A. (2002). Using Interviews in a Research Project. Trent Focus for research and Development in Primary Health Care. Trent Focus. University of Nottingham. 1-25.

Martins, E.C. \& Terblanche, F. (2003). Building organisational culture that stimulates creativity and innovation. European Journal of Innovation Management, 6 (1), 64-74.

McAdam, R \& McClelland, J. (2002). Individual and teambased idea generation within innovation management: organisational and research agendas. European Journal of Innovation Management, 5 (2), 86-97.

McGivern, M.H. \& Tvorik, S.J. (1997). Determinants of organizational performance. Management Decision, 35 (6), 417-435.

Mohamed, M.A.K. (2002). Assessing determinants of departmental innovation: an exploratory multi-level approach. Personnel Review, 31 (5), 620-641.

Mole, V. \& Elliot, D. (1987). Enterprising Innovation: An alternative approach. London: Frances Pinter.

Mouton, J. \& Marais, H.C. (1996). Basic Concepts in the Methodology of the Social Sciences. Pretoria: HSRC Publishers.

Pandit, N.R. (1996). The Creation of Theory: A Recent Application of the Grounded Theory Method. The Qualitative Report, 2 (4).

Parker, L.D. \& Roffey, B.H. (1996). Methodological Themes: Back to the drawing board: revisiting grounded theory and the everyday accountant and manager's reality. Accounting, Auditing \& Accountability Journal, 10 (2), 212-247.

Pauk, W. (1989). The Cornell Note Taking System. On-line study $\underline{\text { skills. }}$. Retrieved from the World Wide Web on 09/04/2003: http.//www.clt.cornell.edu.
Peters, T. \& Waterman, R. (1982). In Search of Excellence: Lessons from America's Best Run Companies. New York: Harper and Row.

Pope, C., Ziebland, S. \& Mays, N. (1999). Qualitative Research in Healthcare. London: BMJ Publishing.

Pyka, A. \& Küppers, G. (2002). Innovation Networks: Theory and Practice. Cheltenham, UK: Edward Elgar.

Quinn, J.B., Baruch, J.J. \& Zien, K.A. (1997). Innovation Explosion: using intellect and software to revolutionize growth strategies. New York: The Free Press.

Radebe, J. (2004). Opening Address: South African Transport Conference. Pretoria. Retrieved from the World Wide Web on 07/05/2003: http://www.transport. gov.za.

Rogers, E.M. (1995). Diffusion of Innovations. New York: The Free Press.

Schurink, W.J. \& Schurink, E.M. (2001). Deciding to use a qualitative research approach. In Schurink, W.J. (ed.) Models of qualitative research. Part One. Department of Human Resource Management. Johannesburg: RAU.

Senge, P.M. (1990). The Fifth Discipline. The art and practice of the learning organization. New York: Doubleday Currency.

Star, S.L. (1997). Grounded Classification: Grounded Theory and Faceted Classification. Conference Paper: Information Systems and Qualitative Research. IFIPS WG 8.2. Retrieved from the World Wide Web on 07/05/2003: http://www.alexia.lis.uiuc.edu/ star/gt.htlm.

Stewart, V. \& Stewart, A. (1990). Business Applications of Repertory Grid. Goodwood, SA: National Printers.

Strauss, A. \& Corbin, J. (1990). Basics of Qualitative Research: Grounded Theory Procedures and Techniques. Thousand Oaks, CA.: Sage.

Strategy document. (Transnet). 2002-2007.

Swan, J.A. \& Newell, S. (1994). Managers' beliefs about factors affecting the adoption of technological innovation: A study using cognitive maps. Journal of Managerial Psychology, 9 (2), 3-11.

Sy, T. \& Côté, S. (2004). Emotional Intelligence: A key ability to succeed in the matrix organization. Journal of Management Development, 23 (5), 437-455.

Tucker, R.B. (2002) Driving Growth through Innovation. How leading firms are transforming their futures. San Francisco: Berrett-Koehler Publishers.

Tucker, R.B. (2003). Innovation and growth. Strategy \& Leadership, 19 (4), 29-31.

Uecke, O. (2002). AIO: An Innovative Organization. Paper within entrepreneurial creativity. Jönköping International Business School. Jönköping University. 1-13.

Urabe, K. (1988). Innovation and the Japanese management system In Urabe, K.; Child, J.; Kagono, T. Walter de Gruyter (eds.) Innovation and management: International comparisons. Berlin. 3-25.

Van Zyl, E. M. (2005). Building blocks of innovation within a stateowned enterprise. Unpublished D Phil-thesis. Johannesburg: University of Johannesburg.

Zhuang, L., Williamson, D. \& Carter, M. (1999). Innovate or liquidate - are all organisations convinced? A two-phased study into the innovation process. Management Decision, 37 (1), 57-71. 
REVIEW PANEL EDITION 3.2

Prof S Brijball-Paramasur

Dr M Coetzee

Prof TA Coetzee

Prof D Coldwell

Ms Z Dannhauser

Dr WS de Villiers

Prof R Doktor

Prof C Hoole

Prof W Jordaan

Prof P Koortzen

Prof R Le Roux

Mr A Moerdyk

Prof B Swanepoel

Prof C Theron

Prof C van Wyk

Prof E van Zyl

Dr A Venter
University of KwaZulu Natal

UNISA

University of Pretoria

University of KwaZulu Natal

University of Stellenbosch

University of Stellenbosch

University of Hawaai

University of Pretoria

Emeritus Professor UNISA

UNISA

University of KwaZulu Natal

Rhodes University

University of Southern Queensland

University of Stellenbosch

North-West University

University of the Free State

University of Johannesburg 